\title{
Safety Analysis of Autologous Stem Cell Therapy in a Variety of Degenerative Diseases and Injuries Using the Stromal Vascular Fraction
}

\author{
Kristin Comella a, b, g, Michelle Parloc, Rosemary Dalyc, Vincent Depasquale ${ }^{\mathrm{d}}$, \\ Eric Edgerton ${ }^{\mathrm{d}}$, Patrick Mallory ${ }^{\mathrm{e}}$, Roy Schmidt ${ }^{\mathrm{f}}$, Walter P. Drake ${ }^{\mathrm{b}}$
}

\begin{abstract}
Background: Stem cells from adipose tissue offer a novel therapy for patients with damaged tissue. Stromal vascular fraction (SVF) injected into patients may reduce inflammation, promote healing, and repair damaged/scarred tissue. SVF can be isolated from fat (adipose) tissue in an outpatient procedure. The SVF population includes mesenchymal stem cells (MSCs), pericytes, endothelial/progenitor cells, fibroblasts and growth factors where the adipocyte (fat cell) population has been removed. Here we describe the use of SVF in the clinic for degenerative diseases in orthopedics, neurological conditions and systemic conditions in 676 patients.
\end{abstract}

Methods: This study demonstrated the strong safety profile from a multi-center analysis of SVF injection in treating various diseases. Approximately $60 \mathrm{~mL}$ of fat tissue was removed from the abdomen or flanks using a local tumescent liposuction procedure. The fat was separated via centrifuge to isolate the SVF and the cells were delivered intraarticularly, intravenously, intrathecally, or intradiscally directly into the same patient. All subjects were monitored for adverse events.

Results: The procedure demonstrates exceptional patient safety, and the study underscores the safety of autologous stem cell therapy in general. Few adverse events were reported and were overwhelmingly of mild and transient nature, such as the expected soreness at the site of liposuction and occasional headache.

Conclusion: The three deaths reported were most likely not related to

Manuscript submitted September 6, 2017, accepted September 25, 2017

aUS Stem Cell, Inc., 13794 NW 4th Street, Suite 212, Sunrise, FL 33325, USA bPanama College of Cell Science, 3rd Floor, C\&H Towers Corner of Great Marlboro and Great George Streets Roseau, 00152, Commonwealth of Dominica

'US Stem Cell Clinic, 12651 Sunrise Blvd, Suite 104, Sunrise, FL 33323, USA ${ }^{\mathrm{d} N S I}$ Stem Cell, 3118 Gulf to Bay Blvd, Suite 310, Clearwater, FL 33759, USA

eMallory Family Wellness, 1548 North Boise Ave., Loveland, CO 80538, USA

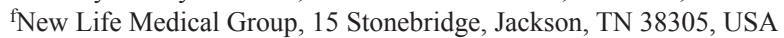

'Corresponding Author: Kristin Comella, US Stem Cell, Inc., 13794 NW 4th

Street, Suite 212, Sunrise, FL 33325, USA.

Email:kcomella@us-stemcell.com

doi: https://doi.org/10.14740/jocmr3187w the treatment but instead to the underlying disease. Our study demonstrates a strong safety profile with low complication rates.

Keywords: Adipose-derived stromal/stem cells; Adipose tissue; Cell therapy; Mesenchymal stem cells; Platelet rich plasma; Regenerative medicine; Stem cells; Stromal vascular fraction

\section{Introduction}

In this study, we report a safety analysis of multiple clinical sites utilizing stromal vascular fraction (SVF) derived from the fat tissue for a variety of diseases and delivered either intravenously, intraarticularly, intrathecally, or intradiscally. Although decades of both preclinical and clinical studies conducted globally have been published showing that adult stem cells are safe and effective, few if any have analyzed the safety of SVF from fat used bedside. We conducted our study at multiple treatment centers in the United States, and the results demonstrate overwhelmingly that this new type of patient-specific medical treatment is safe. It is hoped that our report may be a beneficial starting point for physicians considering this new approach to disease, and helpful also to regulatory agencies seeking to advance policy for the benefit of patients.

Many publications have focused on the tremendous tissue repairing capabilities of mesenchymal stem cells (MSCs) $[1,2]$. Stem cells represent a new paradigm in medicine due to their ability to self-renew and promote a healing cascade. MSCs are known to be anti-inflammatory, anti-scarring, angiogenic and pro-healing. The true mechanism of action is not fully understood but is believed to be part of a complex paracrine activity. A cascade of events with expression of different growth factors and cytokines regulates the regeneration of diseased and damaged tissues and organs. Recent studies have focused on the pericyte as the pre-curser to the MSC. Pericytes coat the microvessels and capillaries throughout the body. These cells are thought to release from their local environment at the time of injury and begin an immunomodulatory effect. The signaling causes other cells to home to the damaged tissue and a regenerative microenvironment is established [3].

Adipose tissue has been recognized as an abundant source of MSCs. The specific type of MSC isolated from fat tissue is 
called an adipose-derived stem cell (ADSC). Mini-lipoaspiration provides access to a large volume of subcutaneous fat and therefore a large population of stem cells [4]. ADSCs are like MSCs in that they can self-renew and differentiate into bone, cartilage, muscle and fat. In addition, various growth factors and cytokines which are associated with wound healing, angiogenesis and vasculogenesis are expressed in this cell population. These signals help to facilitate healing and repair of damaged tissue and play a role in the local inflammatory process $[5,6]$.

The SVF is the cell population that is obtained from the fat tissue after a mini-lipoaspirate procedure. The adipocytes (fat cells) have been removed from the SVF leaving behind a mixture of cells including ADSCs and growth factors. There is a high percentage of $\mathrm{CD} 34^{+}$cells in the SVF which has been shown to be associated with angiogenesis [7]. This protein is expressed on both pericytes and MSCs. Cells in a periendothelial location, which help to stabilize endothelial networks, are typically expressing CD34. SVF has recently been reported as an in-clinic therapy for a variety of indications. Cells from adipose tissue are quickly becoming the preferred source for inclinic therapies due to the high number of stem cells and low number of leukocytes as compared to bone marrow [8]. There is also a high amount of pericytes in adipose tissue as a result of the extensive vascular network $[9,10]$.

Stem cells from adipose tissue offer a novel therapy for patients with damaged tissue. SVF injected may reduce inflammation, promote healing, and repair damaged/scarred tissue. SVF is an attractive therapeutic method given that the harvesting process is safe and the cells are readily available in large quantities. The use of SVF has been reported in a variety of indications including osteoarthritis [11-13], degenerative disc disease [14], sclerosis [15], tendinopathy [16], congestive heart failure [17], chronic obstructive pulmonary disease (COPD) [18], radiation necrosis [19], xerostomia [20], and multiple sclerosis [21].

Here we report a safety analysis of multiple clinical sites utilizing SVF for a variety of indications delivered intravenously, intraarticularly, intrathecally, or intradiscally.

\section{Materials and Methods}

\section{Study design}

Multiple clinical sites throughout the US utilized a standard clinical protocol (trial registration: NCT03226093) to isolate fat tissue and obtain an SVF (US Stem Cell, Inc., Sunrise, FL, protocols and SVF isolation kits). Safety data were collected and analyzed from five clinical sites in the United States. Written informed consent was obtained from all participants. Patients were notified that the medical procedure is considered experimental and is not yet the standard of care. SVF was injected either systemically or locally to the site of injury/disease. All patients were monitored for safety events. Serious adverse events (SAEs) are defined as any event that is fatal or life-threatening, led to hospitalizations, or required major medical intervention. All other events, side effects, or patient complaints/discomforts were collected as adverse events (AEs).

\section{Adipose collection and cell preparation}

The mini-lipo-aspiration was completed under local anesthesia with a modified Kline solution: $500 \mathrm{~mL}$ normal saline, $25 \mathrm{~mL}$ lidocaine $(2 \%), 4 \mathrm{~mL}$ sodium bicarbonate $(8.4 \%)$ and $0.5-1$ $\mathrm{mL}$ epinephrine $(1: 1,000)$. Using an 11 blade, a $3 \mathrm{~mm}$ incision was made in the abdomen, outer thighs, or flanks. Approximately $500 \mathrm{~mL}$ of local anesthetic was pushed into the subcutaneous space using an infiltration cannula and $60 \mathrm{~mL}$ Luer lock syringe. A $3 \mathrm{~mm}$ aspiration cannula attached to a Toomey syringe was used to remove the fat. Pressure was maintained in the syringe using a Toomey snap lock. The SVF was prepared using a commercially available kit (US Stem Cell, Inc., Sunrise, FL). Briefly, the adipose tissue was rinsed with a balanced salt solution and digested using collagenase (Adipocell ${ }^{\mathrm{TM}}$ Enzyme, US Stem Cell, Inc., Sunrise, FL) at $37^{\circ} \mathrm{C}$ for $12-15$ min with agitation at 5 -min intervals. The digested tissue was centrifuged at $1,200 \times \mathrm{g}$ for $5 \mathrm{~min}$ to collect the SVF as a pellet. The pellet was washed twice and filtered through a $100 \mu \mathrm{m}$ cell strainer with a balanced salt solution to remove any residual enzyme. The cells were either resuspended in saline (for IV and intrathecal) or autologous platelet rich plasma (PRP) (for joints, discs and soft tissue) as detailed below.

\section{PRP or serum preparation}

The SVF was resuspended in PRP prior to administration into the joints or soft tissue. In order to prepare PRP, autologous blood was collected in ACD solution A blood tubes using a 22 -gauge butterfly needle. The contents of the blood tubes were transferred to $50 \mathrm{~mL}$ conicals and centrifuged at $500 \mathrm{~g}$ for $8 \mathrm{~min}$. The PRP population just above the buffy coat was collected using cell extractors or aspiration needles and syringes. Approximately $35 \mathrm{~mL}$ of whole blood yielded $3-5 \mathrm{~mL}$ of PRP to resuspend applicable samples.

As an adjunct to the stem cell therapy, patients with reported lung diseases such as COPD were instructed to use autologous serum at home in a nebulizer. Autologous blood was collected in ACD solution A blood tubes and centrifuged at $500 \mathrm{~g}$ for $8 \mathrm{~min}$. The entire yellow serum population above the buffy coat was collected and placed in $3 \mathrm{~mL}$ syringes in 1.5 $\mathrm{mL}$ aliquots. Patients were instructed to keep syringes in the freezer at home and nebulize every 2 - 4 days.

\section{Intravenous (IV) injection}

For patients with systemic symptoms and diseases $(n=246)$, the cells were administered intravenously. The most common patient reported diseases included COPD, heart disease, Lyme disease, Crohn's/colitis, other autoimmune diseases, diabetes and kidney failure. The IV delivery of stem cells is typically administered via IV infusion over 30 - $60 \mathrm{~min}[13,22]$. To reduce cell loss from adherence to polypropylene bag surface, cells were administered via bolus push. Briefly, SVF cell pellets containing approximately $30-60$ million cells were suspended in $3-5 \mathrm{~mL}$ of $0.9 \%$ normal saline. Using a 22 -gauge 
butterfly needle, the contents were injected into a vein. The line was cleared using 3 - $5 \mathrm{~mL}$ of normal saline.

\section{Intrathecal injection}

For patient experiencing neurological symptoms $(n=93)$, the cells were administered intrathecally via lumbar puncture. The most common patient reported diseases included multiple sclerosis, Parkinson's disease, amyotrophic lateral sclerosis, and spinal cord injury. Injection of SVF was previously presented [13]. Briefly, SVF cell pellets were suspended in $2-5 \mathrm{~mL}$ of $0.9 \%$ normal saline. Patients were placed in the sitting, lateral decubitus or prone (jack-knifed) position. Standard sterile preparation was maintained throughout the procedure. Local anesthetics were used only in the skin and subcutaneous tissue. The level of the injection was L3-4 or lower using a midline or paramedian approach with a 25 -gauge, 3.5 -inch spinal needle keeping the bevel parallel to the longitudinal dural fibers.

\section{Intradiscal injection}

For patients with degenerative disc disease $(n=33)$, an intradiscal technique was applied according to Comella et al [14]. In summary, the patients were given IV antibiotics $30 \mathrm{~min}$ prior to the procedure. They were placed in a prone position on a fluoroscopy table. Standard sterile preparation and local anesthesia were administered. The double needle technique was utilized. Proper needle position was confirmed using anteroposterior and lateral fluoroscopic imaging. A small amount of contrast agent containing antibiotics was injected into the nucleus of the disc followed by approximately $1 \mathrm{~mL}$ of SVF/ PRP suspension. If more than one disc was symptomatic, the SVF was divided and prepared with approximately $1 \mathrm{~mL}$ of PRP. Additional PRP and/or SVF may have been injected into the surrounding soft tissue.

\section{Intraarticular injection}

A majority of the patients $(n=264)$ in this study received intraarticular injections for orthopedic symptoms. Patient reported issues included osteoarthritis or soft tissue damage. Typical joint injections have been detailed in previous publications $[11,12]$. The cell pellet was suspended in $3-5 \mathrm{~mL}$ of PRP. Joints were palpated for injection site and prepped using standard sterile techniques. Ethyl chloride was used to numb the skin surface. The cell mixture was injected intraarticularly with a 22-gauge 1.5 -inch needle. Some cases were completed using ultrasound guidance.

\section{Fat transfer injection}

Several patients in the study received cell-assisted fat transfer to the face for aesthetic purposes. Detailed protocols on fat transfer are previously published [23]. Autologous fat transfer is enhanced by adding SVF to the fat. SVF as obtained above was added to $60-100 \mathrm{~mL}$ of fat for lipofilling in the face [24, $25]$.

\section{Intramuscular and scalp injection}

Seven patients received stem cell injections into the scalp for hair loss and one patient intramuscular injections in the legs for vascular disease. In both protocols, the cells were resuspended in 5 - $10 \mathrm{~mL}$ of PRP as described above. Topical lidocaine was applied to the skin surface. A $1 \mathrm{~cm}$ grid pattern was created in the affected area and $0.25 \mathrm{~mL}$ of PRP/SVF mixture was injected using a 30 -gauge 0.5 -inch needle at each point.

\section{Corpus cavernosum and vagina injection}

A total of five patients received injections of stem cells in their sex organs. For male patients with self-reported erectile dysfunction, the SVF was resuspended in $5 \mathrm{~mL}$ of PRP. The corpus cavernosum was infiltrated on each side with $2 \mathrm{~mL}$ of $1 \%$ lidocaine using 30-gauge needles, allowing 2 - 5 min to take effect. SVF/PRP of $2.5 \mathrm{~mL}$ was injected using a 0.5 -inch, 25-gauge needle into proximal end of the shaft on each side at the corpus cavernosum.

For female patients with self-reported vaginal dryness and/or urinary incontinence, the SVF was resuspended in 5 $\mathrm{mL}$ of PRP. The anterior vaginal wall and the clitoral hood was injected with $1 \mathrm{~mL}$ of $1 \%$ lidocaine each using 30-gauge needles. Approximately $4 \mathrm{~mL}$ of the cell mixture was injected into the anterior vaginal wall using a 25 -gauge 1.5 -inch needle. The remaining $1 \mathrm{~mL}$ of cell mixture was injected into the clitoris.

\section{Results}

\section{Adipose and SVF collection}

Mini-lipo-aspirated procedures to collect $60 \mathrm{~mL}$ of fat tissue were well tolerated and uneventful. On average, 30 - 60 million total cells were obtained in the SVF. As reported previously [17], the population obtained is at least $50 \%$ positive for CD34 with a viability of greater than $90 \%$. The cells have also demonstrated the ability to differentiate down pathways of adipogenesis (fat), osteogenesis (bone) and chondrogenesis (cartilage).

\section{Patient demographics}

Patients were treated for a variety of indications including neurological or systemic symptoms, orthopedic conditions and aesthetic enhancement. Neurological conditions addressed with an intrathecal injection included Parkinson's, multiple sclerosis, spinal cord injury, ALS, traumatic brain injury, progressive supranuclear ophthalmoplegia, dementia, stroke and more. Systemic conditions addressed with an IV deliv- 


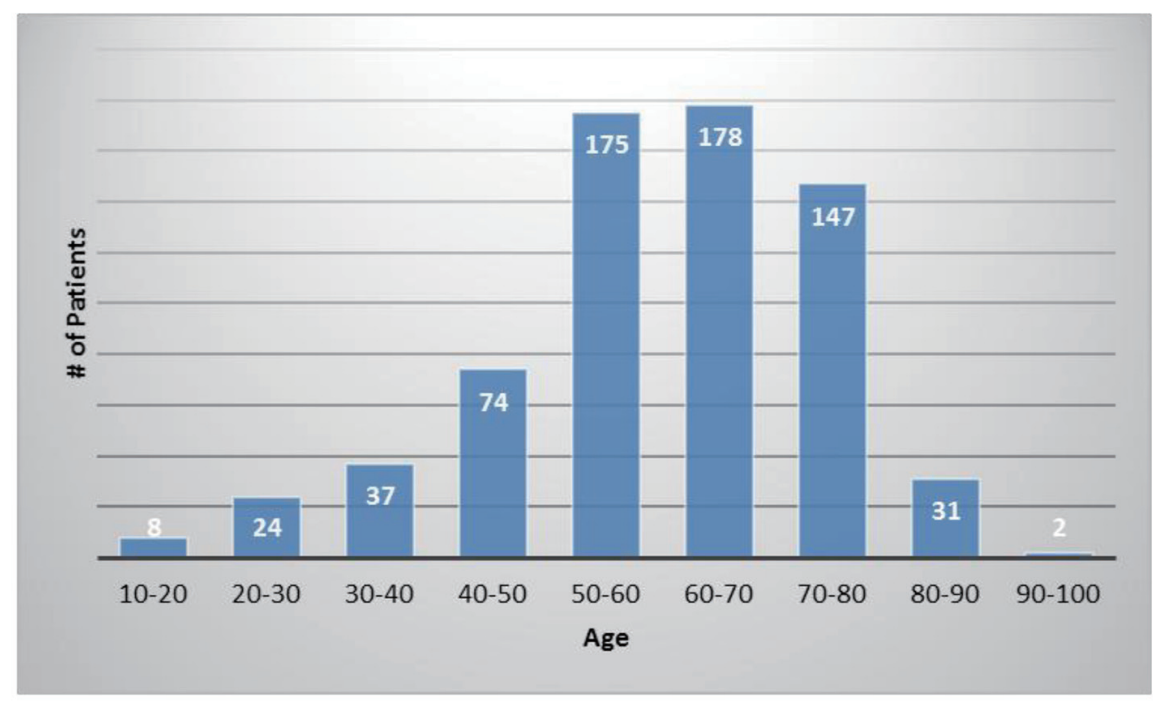

Figure 1. The number of patients in each age category.

ery included diabetes, COPD, pulmonary fibrosis, rheumatoid arthritis, Crohn's/colitis, heart disease, kidney disease, polymyositis, psoriasis, other autoimmune disorders, and more. Orthopedic conditions included osteoarthritis, acute tendon/ ligament injuries, degenerative disc disease, and more. Some patients also received injections into the corpus cavernosum for erectile dysfunction or into the vaginal wall for bladder control or vaginal dryness.

The average patient age was 59.6 years with a range of 15 - 97 years and $49.9 \%$ were male and $50.1 \%$ were female. Figure 1 shows the number of patients in each age range. Most patients fell in the age category of $60-70$ followed by $50-60$ and $70-80$. Only two patients over the age of 90 and eight patients below 20 were treated. Figure 2 summarizes by percentage the type of injections and the number of patients for each category shown in parentheses. The most common injec- tion was intraarticular with 284 patients followed by 246 IV injections. Ninety-three patients received intrathecal injections for neurological symptoms and 33 intradiscal for back conditions. The other routes of administration included less than 10 patients each. Figure 3 shows the patient reported indications and diseases. In some cases, the patient reported more than one indication. The most common reported disease was osteoarthritis followed by lung disease (predominantly COPD).

\section{Safety analysis}

Overall, the procedures demonstrated a strong safety profile with very few reported SAEs or AEs. Figure 4 shows a summary of the patient reported SAEs and AEs by injection type. A total of 23 AEs and four SAEs were reported throughout

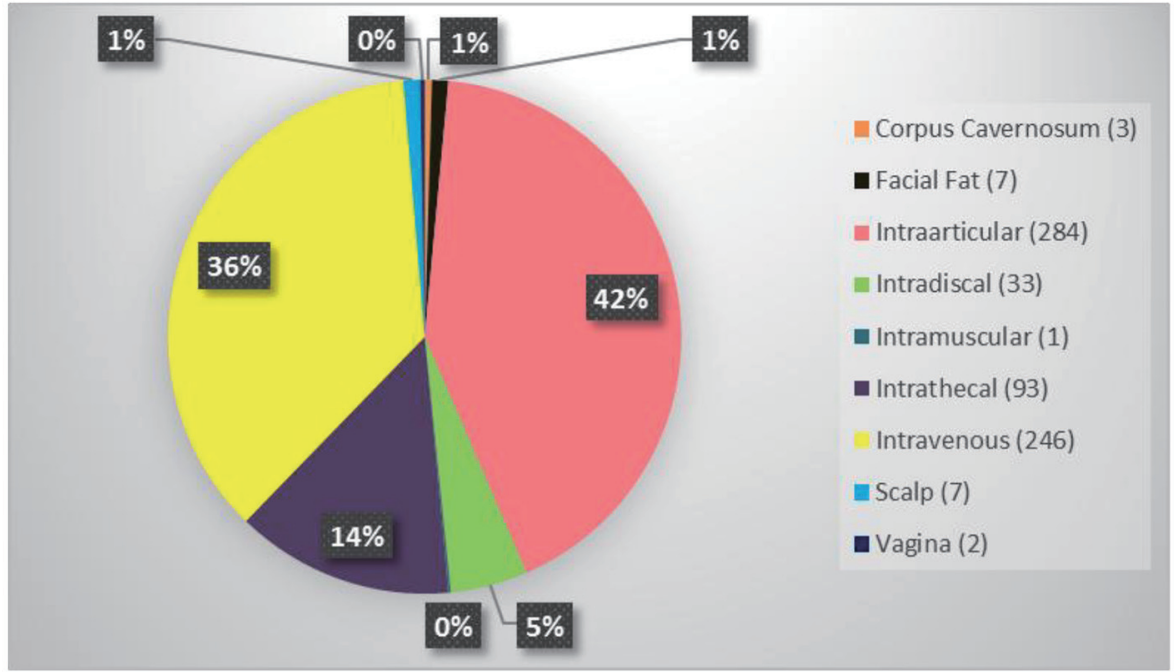

Figure 2. Summary of the type of stem cell injections and the number of patients who received in parenthesis. 


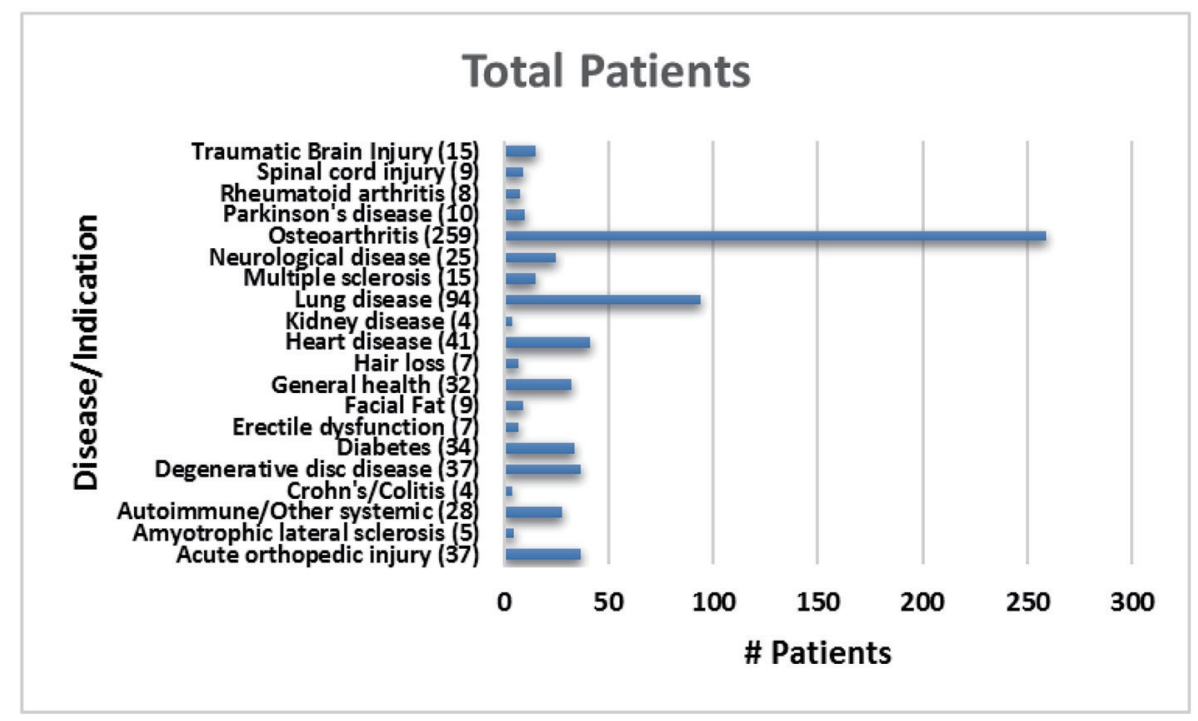

Figure 3. Total number of patients treated for each reported indication.

the 12-month follow-up period. This corresponds to $3.4 \%$ AEs and $0.59 \%$ SAEs for SVF injections. Figure 5 shows the total number of patients per indications with total numbers in parentheses. Reported SAEs and AEs by indication are shown by percentage in red. Note that some patients reported more than one indication or disease. Patients with various neurological diseases had greater than $84 \%$ safety profile (i.e. four AEs out of 25 patients) indicating a very solid safety record for intrathecal injections. Other neurological indications such as Parkinson's and multiple sclerosis had a higher safety percent-

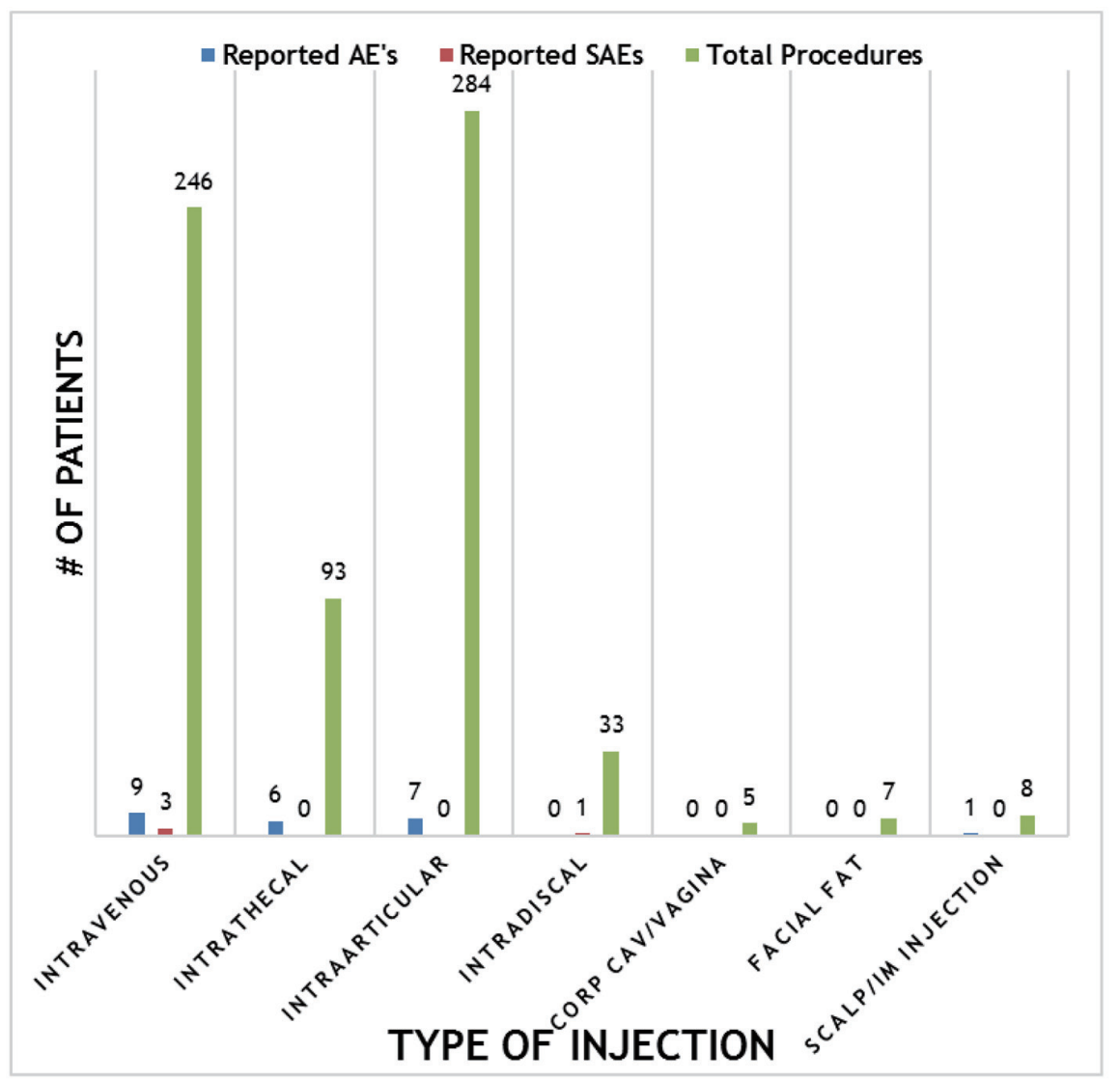

Figure 4. Summary of reported adverse events (AEs) and severe adverse events (SAEs) per method of injection. 


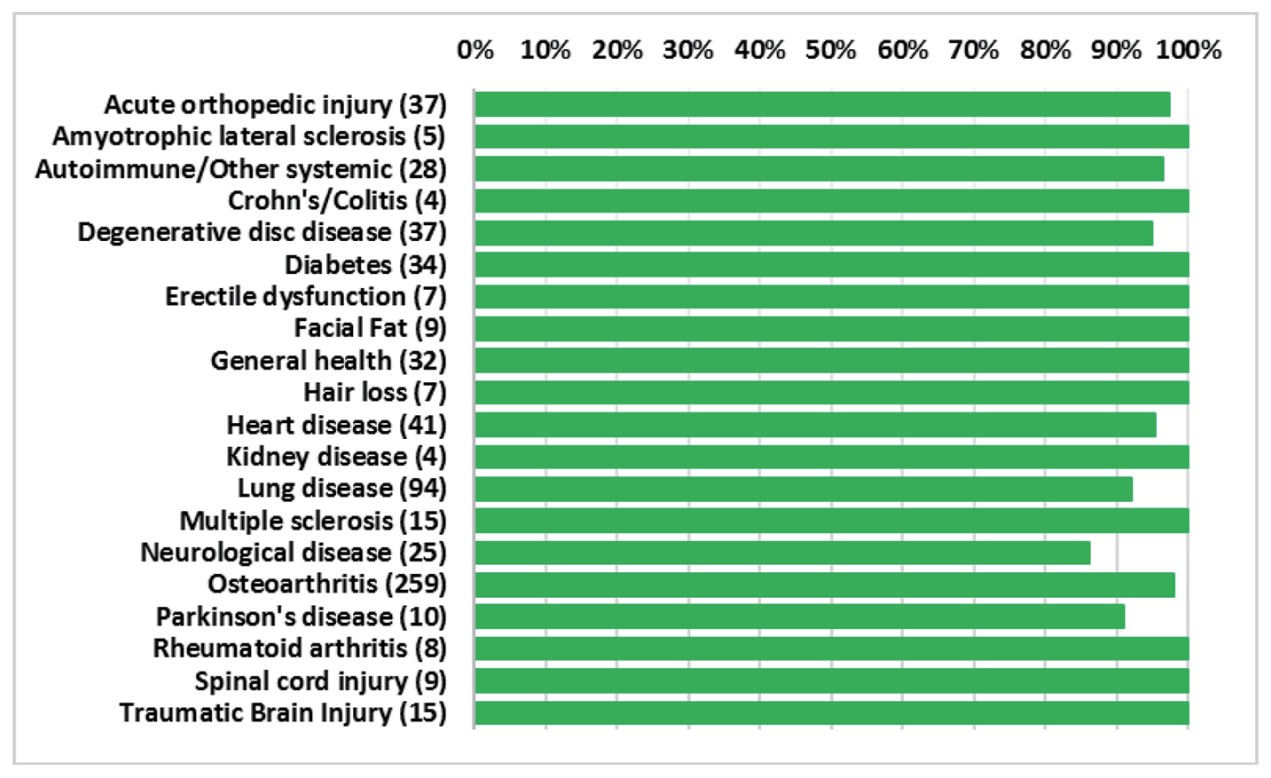

Figure 5. Percentage of patients for each indication with no adverse events. Total number of patients shown in parentheses.

age ( $90 \%$ and $100 \%$, respectively), but this may be due to the small number of patients in each group. All other indications had a greater than $90 \%$ safety profile.

Included in the SAEs, there were three reported patient deaths. One patient with end-stage COPD who required continuous supplemental oxygen was hospitalized with pneumonia after the procedure. His condition continued to worsen and the patient died approximately 1 month after procedure. Another patient who had received a joint injection died 3 weeks after therapy and the autopsy report confirmed a drug overdose. A third patient died approximately 11 months after IV SVF administration from suspected complications of cardiovascular disease. A fourth SAE that required hospitalization of potential discitis was reported. The patient was treated with a 6-week course of outpatient IV antibiotics via a picc line. A fluoroscopic-guided biopsy of the affected lumbar vertebra after treatment was negative.

Other AEs included soreness/swelling at the liposuction site or site of injection. Some patients who received an IV injection reported elevated body temperature $24-48 \mathrm{~h}$ after the procedure. Patients were instructed to take acetaminophen for pain and/or fever and all events resolved without further complications. Two patients had superficial skin irritation at liposuction site. Both were treated with oral Kelfex $500 \mathrm{mg}$ twice a day for 5 days with complete resolution. Some patients who had received intrathecal injections described non-postural headaches, nerve pain sensations or difficulty moving. Headaches typically lasted $24-72 \mathrm{~h}$ and were managed with acetaminophen. Also, the reported increased nerve sensations/pains lasted for approximately 1 month and resolved without further intervention. Several patients who were being treated for lung disease were also using serum as described above in a nebulizer. Many of these patients reported increased congestion at the beginning, possibly due to the loosening of the congested lung mucus. These issues were also resolved without further intervention.

\section{Discussion}

The collected results demonstrate that SVF from fat containing autologous stem cells can be safely obtained and injected into patients. The compilation of safety patient outcomes after delivery of SVF via different routes presented in the figures of this manuscript is example of the strong safety profile. The recorded patient complaints included expected side effects from liposuction or injection such as soreness or headaches. All of the reported side effects were included in the patient consents as possible or expected outcomes to the medical procedure. Two of SAEs reported were deemed mostly likely not related to the stem cell treatment but instead to the underlying disease of the patient. A third AE was confirmed drug overdose not related to therapy or procedure. The final $\mathrm{AE}$ is considered an expected possible outcome to the injection procedure. These SAEs can be considered coincidental incidents rather than related directly to the safety of autologous SVF stem cell therapy. If we set aside the questionable AEs above, the only side effects remaining are those anticipated procedural discomforts.

\section{Conclusion}

Our reported results from five treatment centers in the United States demonstrate the overall safety of autologous stem cell therapy using stem cells from the SVF collected from liposuction of fat tissue. The few serious adverse side effects reported were deemed most likely not related to stem cell therapy received nor to the procedure used. Consequently, our paper adds further documentation to the global safety record of adult stem cell therapy. 


\section{Consent}

All patients were consented and agreed to participate in treatments.

\section{Competing Interests}

$\mathrm{KC}$ is an officer of US Stem Cell, Inc.

\section{Funding}

This study was partially funded by US Stem Cell, Inc.

\section{Author Contributions}

All authors participated in clinic patient treatments and data collection. KC analyzed the data and wrote the manuscript. All authors read and approved the final manuscript.

\section{Abbreviations}

AE: adverse event; COPD: chronic obstructive pulmonary disease; SVF: stromal vascular fraction; PRP: platelet rich plasma; ADSCs: adipose-derived stem/stromal cells; MSC: mesenchymal stem cell; SAE: severe adverse event

\section{References}

1. Hematti P, Keating A. Mesenchymal stromal cells in regenerative medicine: A Perspective. In: Hematti P, Keating A, eds. Mesenchymal stromal cells. Biology and clinical applications. New York, NY: Humana Press; 2013: p. 3-16.

2. Przybyt E, Harmsen MC. Mesenchymal stem cells: promising for myocardial regeneration? Curr Stem Cell Res Ther. 2013;8(4):270-277.

3. Caplan AI, Correa D. The MSC: an injury drugstore. Cell Stem Cell. 2011;9(1):11-15.

4. Minteer D, Marra KG, Rubin JP. Adipose-derived mesenchymal stem cells: biology and potential applications. Adv Biochem Eng Biotechnol. 2013;129:59-71.

5. Gimble JM, Katz AJ, Bunnell BA. Adipose-derived stem cells for regenerative medicine. Circ Res. 2007;100(9):1249-1260.

6. Rehman J, Traktuev D, Li J, Merfeld-Clauss S, Temm CJ, Bovenkerk JE, Pell C, Johnstone B, Considine RV, March KL. The secretion of angiogenic and anti-apoptotic factors by human adipose stromal cells. Circulation. 2004;109(10):1291-1298.

7. Traktuev DO, Merfeld-Clauss S, Li J, Kolonin M, Arap W, Pasqualini R, Johnstone BH, et al. A population of multipotent CD34-positive adipose stromal cells share pericyte and mesenchymal surface markers, reside in a periendothelial location, and stabilize endothelial networks. Circ Res. 2008;102(1):77-85.

8. Panfilov IA, de Jong R, Takashima S, Duckers HJ. Clinical study using adipose-derived mesenchymal-like stem cells in acute myocardial infarction and heart failure. Methods Mol Biol. 2013;1036:207-212.

9. Jang Y, Koh YG, Choi YJ, Kim SH, Yoon DS, Lee M, Lee JW. Characterization of adipose tissue-derived stromal vascular fraction for clinical application to cartilage regeneration. In Vitro Cell Dev Biol Anim. 2015;51(2):142150.

10. Aust L, Devlin B, Foster SJ, Halvorsen YD, Hicok K, du Laney T, Sen A, et al. Yield of human adipose-derived adult stem cells from liposuction aspirates. Cytotherapy. 2004;6(1):7-14.

11. Michalek J, Moster R, Lukac L, Proefrock K, Petrasovic M, Rybar J, Capkova M, et al. WITHDRAWN: Autologous adipose tissue-derived stromal vascular fraction cells application in patients with osteoarthritis. Cell Transplant. 2015.

12. Bansal H, Comella K, Leon J, Verma P, Agrawal D, Koka P, Ichim T. Intra-articular injection in the knee of adipose derived stromal cells (stromal vascular fraction) and platelet rich plasma for osteoarthritis. J Transl Med. 2017;15(1):141.

13. Siennicka K, Zolocinska A, Stepien K, Lubina-Dabrowska N, Maciagowska M, Zolocinska E, Slysz A, et al. Adipose-derived cells (stromal vascular fraction) transplanted for orthopedical or neurological purposes: are they safe enough? Stem Cells Int. 2016;2016:5762916.

14. Comella K, Silbert R, Parlo M. Effects of the intradiscal implantation of stromal vascular fraction plus platelet rich plasma in patients with degenerative disc disease. $\mathrm{J}$ Transl Med. 2017;15(1):12.

15. Daumas A, Magalon J, Jouve E, Truillet R, Casanova D, Giraudo L, Veran J, et al. Long-term follow-up after autologous adipose-derived stromal vascular fraction injection into fingers in systemic sclerosis patients. Curr Res Transl Med. 2017;65(1):40-43.

16. Usuelli FG, Grassi M, Maccario C, Vigano M, Lanfranchi L, Alfieri Montrasio U, de Girolamo L. Intratendinous adipose-derived stromal vascular fraction (SVF) injection provides a safe, efficacious treatment for Achilles tendinopathy: results of a randomized controlled clinical trial at a 6-month follow-up. Knee Surg Sports Traumatol Arthrosc. 2017.

17. Comella K, Parcero J, Bansal H, Perez J, Lopez J, Agrawal A, Ichim T. Effects of the intramyocardial implantation of stromal vascular fraction in patients with chronic ischemic cardiomyopathy. J Transl Med. 2016;14(1):158.

18. Comella K, Blas JAP, Ichim T, Lopez J, Limon J, Moreno $\mathrm{RC}$. Autologous stromal vascular fraction in the intravenous treatment of end-stage chronic obstructive pulmonary disease: a phase $\mathrm{i}$ trial of safety and tolerability. J Clin Med Res. 2017;9(8):701-708.

19. Parcero J, Perez J A, Patel A, Ichim T, Gonzalez S, McQuillan S, Comella K. Autologous adipose derived stromal stem cell implantation to resolve critical limb ischemia: case report. Cureus. 2014;6(5):e182. 
20. Comella K, Bell W. First-in-man intraglandular implantation of stromal vascular fraction and adipose-derived stem cells plus platelet-rich plasma in irradiation-induced gland damage: a case study. Int Med Case Rep J. 2017;10:295-299.

21. Riordan NH, Ichim TE, Min WP, Wang H, Solano F, Lara F, Alfaro M, et al. Non-expanded adipose stromal vascular fraction cell therapy for multiple sclerosis. J Transl Med. 2009; 7:29.

22. Lander EB, Berman MH, See JR. Safety of stromal vascular fraction cells applications in chronic pain. Tech- niques in Regional Anesthesia and Pain Management. 2015;19(1-2):10-13.

23. Laloze J, Varin A, Bertheuil N, Grolleau JL, Vaysse C, Chaput B. Cell-assisted lipotransfer: Current concepts. Ann Chir Plast Esthet. 2017.

24. Sasaki GH. The safety and efficacy of cell-assisted fat grafting to traditional fat grafting in the anterior mid-face: an indirect assessment by 3D imaging. Aesthetic Plast Surg. 2015;39(6):833-846.

25. Glasgold RA. Complementary fat grafting of the face. Autologous Fat Transfer. 2009;209-216. 